\title{
Comparison of hemodynamic responses to dexmedetomidine versus esmolol in patients undergoing beating heart surgery
}

\author{
Mohamed Abdel Rahman Salem M.D,* Mostafa Elhamamsy M.D,** \\ Ashraf Darwish M.D**** \\ *Anesthesia department faculty of medicine Menofyia university \\ **Anesthesia department faculty of medicine Cairo university (Elfayoum Br.) \\ ***Anesthesia department Researsh Institute of Ophthalmology
}

\begin{abstract}
Background: Alpha 2-adrenergic agonists decrease sympathetic tone with ensuing attenuation of neuroendocrine and hemodynamic responses to anesthesia and surgery. Also, administration of beta -adrenergic antagonists contributes to prophylaxis against hypertension, tachycardia and myocardial ischemia and myocardial protection during cardiac surgery. The effects of dexmedetomidine (DEX), a highly specific alpha 2 -adrenergic agonist, on these responses have not yet been fully reported in patients undergoing cardiac surgery. Esmolol (ESM) is a cardioselective, short-acting $\beta$ blocking agent. Previous studies have established the effectiveness of esmolol in the reduction of hemodynamic responses during anesthetic induction.

Aim: The study of hemodynamic responses of dexmedetomidine and esmolol and their effects on the anesthetic requirements during anesthesia in beating heart surgery.

Methods: Forty patients scheduled for elective beating heart surgery received a dexmedetomidine $1 \mathrm{ug} / \mathrm{kg}$ over $10 \mathrm{~min}$ before anesthesia was induced and $0.5 \mathrm{ug} / \mathrm{kg} / \mathrm{h}$ thereafter until the end of surgery in the DEX group and a loading dose of $0.5 \mathrm{mg} / \mathrm{kg}$ esmolol IV was given over 5 min followed by a continuous infusion of $50 \mathrm{ug} / \mathrm{kg} / \mathrm{h}$ until end of surgery in the ESM group. Total intravenous anesthesia using fentanyl, cisatracurium and propofol and oxygen air mixture (40\%-60\%) was used until the end of surgery. Hemodynamics measured included heart rate, mean arterial pressure, filling pressures, cardiac index, systemic and pulmonary vascular resistances. The incidence of hypotension, hypertension, tachycardia, bradycardia, dysrhythmias, ST segment changes, total anesthetics requirements, muscle rigidity and postoperative shivering were recorded.

Results: DEX significantly decreased HR and CI to after to $70 \pm 6 \mathrm{bpm}$ and $2.2 \pm 0.1 \mathrm{l} / \mathrm{min} / \mathrm{m}^{2}(\mathrm{p}<0.05) 3 \mathrm{~min}$ then, increased HR and CI significantly to baseline recording to $77 \pm 9 \mathrm{bpm}$ and $2.5 \pm 0.1 \mathrm{1} / \mathrm{min} / \mathrm{m}^{2}(\mathrm{p}<0.05)$ after $10 \mathrm{~min}$ from the start of infusion. In the postinduction period HR insignificantly decreased to $71 \pm 8 \mathrm{bpm}$ after sternotomy about $65 \mathrm{~min}$ from the start of infusion. The postinduction period showed insignificant gradual increase in HR to $79 \pm 6 \mathrm{bpm}$ while, CI continued to be below or at the baseline reading till it reached the baseline recording at the end of surgery. ESM dropped HR insignificantly at 3 min of infusion to $73 \pm 8 \mathrm{bpm}$ and significantly dropped CI to $2.1 \pm 0.31 / \mathrm{min} / \mathrm{m}^{2}(\mathrm{p}<0.01)$. HR and CI continued to show insignificant changes till the end of surgery but HR exceeded the baseline readings and CI did not reach it. DEX significantly increased MAP and SVRI to $101 \pm 13 \mathrm{mmHg}(\mathrm{p}<0.05)$ and $3985 \pm 243$ dyn.s.cm ${ }^{5} . \mathrm{m}^{-2}(\mathrm{p}<0.01)$ at $3 \mathrm{~min}$ of infusion then significantly decreased to baseline reading to $89 \pm 10 \mathrm{mmHg}$ and $2428 \pm 276 \mathrm{dyn} . \mathrm{s} . \mathrm{cm}^{-5} \cdot \mathrm{m}^{-2}$ at $10 \mathrm{~min}$ time interval. MAP
\end{abstract}




\section{Comparison of hemodynamic responses}

continued to decrease till it developed a significant drop to $74 \pm 9 \mathrm{mmHg}$ poststernotomy around 65 min after the start of infusion and gradually increased insignificantly to $78 \pm 6$ $\mathrm{mmHg}$ at the end of surgery while, SVRI did not show any significant changes. In ESM group, MAP was decreased significantly to $87 \pm 14 \mathrm{mmHg}(\mathrm{P}<0.05) 3 \mathrm{~min}$ after the start of infusion and did not show any significant change till the end of surgery while, SVRI did not show significant changes during different studied time intervals. The CVP, PCWP, MPAP and PVRI did not show any statistically significant change at the study time intervals in both groups. DEX had less incidence of intraoperative bradycardia ( 2 vs. 4 patients), tachycardia ( 0 vs. 2 patients), hypertension (0 vs 2 ), hypotension (2 vs 4 ) and ST changes (1 vs5). DEX also decreased the requirements of fentanyl $(26.3 \pm 4.3$ vs $35.4 \pm 5.1 \mathrm{ug} / \mathrm{kg}))$, propofol $(810 \pm 43 \mathrm{vs} 935 \pm 52 \mathrm{mg})$ and midazolam. The incidence of fentanyl-induced muscle rigidity (5 vs 12 patients) and postoperative shivering (4 vs 13 patients) were less in DEX group than ESM group.

Conclusion: Dexmedetomidine in patients undergoing beating heart surgery decreased intraoperative sympathetic tone, induced sedation, attenuated hyperdynamic responses to anesthesia and surgery and overall hemodynamic variability than esmolol. The need for anesthetics, muscle rigidity, perioperative myocardial ischemia and shivering were less also in DEX group.

\section{Introduction}

Administration of beta-adrenergic antagonists contributes to myocardial protection during cardiac surgery. Esmolol is a cardioselective, shortacting $\beta$-blocking agent. Because it is rapidly metabolized by an aryl esterase in the blood, its elimination half-life is only $9 \mathrm{~min} .^{1}$ Thus, the negative inotro pic effect of $\beta$-adrenergic antagonism may not be an issue if esmolol is infused during anesthesia. Previous studies have established the effective ness of bolus doses of esmolol in the reduction of hemodynamic responses during anesthetic induction. ${ }^{2}$ However, prevention of the hemodynamic respo nses to intubation has not been complete. ${ }^{3,4}$ In addition, cardiac arrhy thmias as prolonged QT interval syndrome or an acute myocardial infarc -tion have occurred during anesthesia. ${ }^{5,6}$

Although $\beta$-adrenergic blockade is often a useful therapeutic approach, it may not always be practical in the setting of preexisting bronchospasm or reactive airway disease. ${ }^{7}$ Because of the potential adverse effects of persistent tachycardia that failed to respond to

esmolol or myocardial ischemia especi ally during beating-heart surgery, it was suggested that dexmedetomidine repres -ents a potentially useful therap -eutic approach when treating such patients. ${ }^{8}$ Dexmedetomidine is a more specific and selective $\alpha_{2}$ agonist and has a shorter duration of action than clonidine. It produces dose-dependent sedation and analgesia. ${ }^{9}$ These prope rties make it theoretically a suitable agent for use as a part of an anesthetic regimen in patients undergoing beating heart surgery. In patients having noncardiac surgery, perioperative adminis tration of dexmedetomidine decreases the need for anesthetics and induces sympatholysis with ensuing hemody namic and neuroendocrine stability. ${ }^{10}$

\section{Aim of work}

The aim of the present study was to compare the hemodynamic responses to esmolol infusion and that of dexmed -etomidine infusion during beating heart operations. As secondary variables, were also the effects of both drugs on the occurrence of perioperative 


\section{Comparison of hemodynamic responses}

myocardial ischemia, fentanylinduced muscle rigidity, requirements for anest -hetics, and on postoperative shivering.

\section{Patients and Methods}

After written informed consent was obtained during the preoperative interview, forty patients scheduled for beating heart surgery were randomized to two groups: the ESM group $(n=20)$, and DEX group $(\mathrm{n}=20)$.

Exclusion criteria included ASA physical status $\mathrm{V}$, a myocardial infarc tion within one week before surgery, evidence of renal or hepatic failure, history of severe asthma, or history of allergy or idiosyncratic reaction to $\beta$ adrenergic blocking drugs. Ejection fraction and left ventricular enddiastolic pressure were obtained from the cardiac catheterization report. The patients received their regular antia nginal medication till surgery. Electrocardiographic (ECG) informat ion recorded included rhythm, presence of ST- or T-wave changes, PR interval, QRS duration, QT interval, and R-R interval. ST depressions greater than $0.6 \mathrm{~mm}$ were considered significant.

All patients were premedicated with midazolam $0.1 \mathrm{mg} / \mathrm{kg}$, morphine $0.1 \mathrm{mg} / \mathrm{kg}$, and scopolamine $0.2-0.3 \mathrm{mg}$ intramuscularly approximately $60-90$ min prior to arrival in the operating room.

Prior to induction of anesthesia, ECG leads II and V5 were continuously recorded. After placement of peripheral intravenous (IV) lines and a radial arterial line, a Becton Dickinson (Criticath ${ }^{\mathrm{TM}}$ SP 5107HTD) pulmonary artery catheter was positioned for rea dings of cardiac output ( HP Component Monitoring system M1094A Hewlett Packard, Palo Alto, CA). All baseline measurements were taken after a 5-min stabilization period.
These included heart rate (HR), mean arterial pressure [MAP], central venous pressure (CVP), mean pulmonary arterial pressure [MPAP], pulmonary artery wedge pressure (PAWP), and cardiac output (CO). The study drug infusion (dexmedetomidine or esmolol) was then commenced. The infusion rate of dexmedetomidine was set to deliver $1 \mathrm{ug} / \mathrm{kg} / \mathrm{min}$ for $10 \mathrm{~min}$ before anesthesia was induced and $0.5 \mathrm{ug} / \mathrm{kg} / \mathrm{h}$ thereafter until the end of surgery in the DEX group. A loading dose of $0.5 \mathrm{mg} / \mathrm{kg}$ esm -olol IV was given over 5 min followed by a continuous infusion of $50 \mathrm{ug} / \mathrm{kg} / \mathrm{h}$ until end of surgery in the ESM group. Prior anesthesia induction, hemodyn -amic measurements were recorded after the 3, 10 and $20 \mathrm{~min}$ (before induction) after the start of infusion of the study drug.

Anesthesia was induced with propofol $0.5-1 \mathrm{mg} / \mathrm{kg}$ then, $10 \mathrm{ug} / \mathrm{kg}$ fentanyl was given in 5 min. During fentanyl infusion, ventilation was assis ted manually with $100 \%$ oxygen. If clinically significant, fentanyl-induced chest wall muscle rigidity developed (recorded as yes or no) $0.15 \mathrm{mg} / \mathrm{kg}$ cisatracurium was given immediately. Otherwise cisatracurium was adminis tered for muscle relaxation 1 min after completion of the fentanyl infusion. The patients were intubated when the hemo -dynamic measurements were made and muscle relaxation was complete. After intubation, anesthesia was maintained with a continuous infusion of fentanyl (3 ug/kg/h), cisatracurium $(0.3 \mathrm{ug} / \mathrm{kg} / \mathrm{h}$ ), continuous propofol infusion 4-6 $\mathrm{mg} / \mathrm{kg} / \mathrm{h}$ and oxygen air mixture (40\%-60\%). Supplementary anesthe tics and other drugs (an increase or a decrease of supplemental fentanyl, mid -azolam, administration of a fluid challenge, ephedrine, dopamine, or gly ceryl trinitrate) were administered stepwise according to prespecified 
hemodynamic criteria. Ringer's lactate solution was infused at an approximate rate of $10 \mathrm{ml} / \mathrm{kg} / \mathrm{h}$. Controlled mechan -ical ventilation was adjusted to maintain end-tidal carbon dioxide between 34 and $40 \mathrm{mmHg}$.

Hemodynamic measurements were obtained after intubation (The hemodynamic response to tracheal intub -ation was determined as maximal incr eases in MAP, and HR within $10 \mathrm{~min}$ after intubation versus baseline values), skin incision, sternotomy, and at the end of surgery. Calculated indices used to compare cardiovascular function betw een the two groups are as follows: Cardiac index $\left(\mathrm{CI}, \mathrm{L} / \mathrm{min} / \mathrm{m}^{2}\right)=$ $\mathrm{CO} / \mathrm{BSA}$, where $\mathrm{CO}$ is cardiac output $(\mathrm{L} / \mathrm{min})$ and BSA is body surface area $\left(\mathrm{m}^{2}\right) ;$ Stroke volume index $\left(\mathrm{SVI}, \mathrm{mL} / \mathrm{m}^{2}\right)$ $=\mathrm{CI} / \mathrm{HR}$, where HR is heart rate $(\mathrm{bpm})$; Systemic vascular resistance index (SVRI, dyne.s. $\left.\mathrm{cm}^{-5} \cdot \mathrm{m}^{-2}\right)=($ MAPCVP)/CI x 80; and Pulmonary vascular resistance index (PVRI, dyne.s. $\mathrm{cm}^{-5} \cdot \mathrm{m}^{-}$ $\left.{ }^{2}\right)=($ MPAP-PAWP $) /$ CI x 80.

At the end of surgery, the study drug infusion was discontinued and the patient was transferred to the surgical intensive care unit. The lungs were ventilated after operation until stable hemodynamics and clinically adequate recovery from anesthesia and restor ation of spontaneous respiration were achieved. Meperidine was admin istered in $12.5 \mathrm{mg}$ increments for pain control and shivering. Postoperative shivering was recorded as "yes" or "no". Fluid loading and vasoactive medication were administered accor ding to clinical hemodynamic criteria.

\section{Statistical Analysis}

The results were reported as mean values \pm standard deviations (SD). Hemodynamic data were analyzed with repeated-measures analysis of variance (ANOVA) to compare changes within each group and paired Student's t-test to compare different group data. Significance was $\mathrm{P}<0.05$.

\section{Results}

The demographic characteristics were similar in both groups with respect to age, weight, height, sex distribution, number of patients with previous myoca -rdial infarction, ASA physical status, and the number of patients taking preoperative beta blockers or calcium antagonists medication. There were no differences in physical examination variables and cardiac function (ejection fraction). The duration of surgery, and anesthesia; the number and type of the grafts were also similar in both groups as seen in table (1).

Table (1): Demographic data of both groups (mean $\pm \mathrm{SD}$ )

\begin{tabular}{|l|c|c|}
\hline Parameter & DEX group & ESM group \\
\hline Age $(\mathrm{yr})$ & $55.3 \pm 8.3$ & $57.3 \pm 6.7$ \\
Weight $(\mathrm{kg})$ & $79.2 \pm 11$ & $77.5 \pm 7.6$ \\
Height $(\mathrm{cm})$ & $174 \pm 9$ & $170 \pm 12$ \\
Male/female & $14 / 6$ & $15 / 5$ \\
ASA class III/IV & $16 / 4$ & $17 / 3$ \\
Previous MI & 6 & 4 \\
$\beta$-blockers & 14 & 13 \\
Ca-antagonists & 9 & 11 \\
Ejection fraction & $53 \pm 4$ & $52 \pm 5$ \\
Duration of anesthesia & $255 \pm 28$ & $261 \pm 31$ \\
Duration of surgery & $175 \pm 24$ & $181 \pm 19$ \\
\hline
\end{tabular}




\begin{tabular}{|l|l|l|}
\hline Number of grafts & $3.2 \pm 1$ & $3.3 \pm 1$ \\
\hline
\end{tabular}

Changes in Hemodynamic Variables

During the Study:

Changes in HR with time in the preinduction period during DEX infusion showed a significant decrease to $70 \pm 6 \mathrm{bpm}(\mathrm{p}<0.05)$ after $3 \mathrm{~min}$ from the start of infusion. Then, it was increased significantly to baseline reco rding to $77 \pm 9(\mathrm{p}<0.05)$ after $10 \mathrm{~min}$ from the start of infusion (table: 2). During the postinduction period the changes in HR with time did not show any significant change apart from an insignificant decrease to $71 \pm 8 \mathrm{bpm}$ after sternotomy about $65 \mathrm{~min}$ from the start of infusion and did not show any change till the end of surgery ( table: 3 ). Two patients in this group developed junctional escape rhythm and infrequent premature beats was noticed in another patient (table:4). The HR dropped insignificantly in the ESM group at 3 min infusion to $73 \pm 8 \mathrm{bpm}$ during the preinduction period and continued to decrease insignificantly to $70 \pm 8 \mathrm{bpm}$ before intubation. The changes in HR with time during the postinduction period showed insignificant gradual increase in HR to $79 \pm 6 \mathrm{bpm}$ at the end of surgery. Two patients in the ESM group developed persistent tachycardia not responding to an increase in ESM infusion and one patient developed atrial fibrillation as shown in table (2),(3) and (4). So, dexmedetomidine reduced the HR more than esmolol and maintained this change till the end of surgery.

Changes in MAP with time during DEX loading period showed a significant increase to $101 \pm 13 \mathrm{mmHg}$ $(p<0.05)$ at $3 \mathrm{~min}$ from the start of infusion then significantly decreased to baseline reading to $89 \pm 10 \mathrm{mmHg}$ $(\mathrm{p}<0.05)$ at $10 \mathrm{~min}$ time interval. MAP continued to decrease with time insignificantly in the pre and postinduction period till it developed a significant drop to $74 \pm 9 \mathrm{mmHg}$ postst ernotomy around $65 \mathrm{~min}$ after the start of infusion and gradually increased insignificantly to $78 \pm 6 \mathrm{mmHg}$ at the end of surgery. In ESM group, MAP was decreased significantly to $87 \pm 14$ $\mathrm{mmHg}(\mathrm{P}<0.05) 3 \mathrm{~min}$ after the start of infusion and did not show any significant change till the end of surgery as shown in table (2) and (3).

The CVP, MPAP and PCWP did not show any statistically significant change at the study time intervals in both groups as presented in table (2) and (3).

Changes in CI with time during DEX infusion showed a significant reduction to $2.2 \pm 0.11 / \mathrm{min} / \mathrm{m}^{2} \quad(p<0.05)$ after $3 \mathrm{~min}$ from the start of infusion and significantly increased to $2.5 \pm 0.1$ $1 / \mathrm{min} / \mathrm{m}^{2}$ after $10 \mathrm{~min}$ time interval and continued to be below or at the baseline reading during the postinduction period till it reached the baseline recording at the end of surgery. ESM produced a significant drop in CI after $3 \mathrm{~min}$ from the start of infusion to $2.1 \pm 0.3 \mathrm{1} / \mathrm{min} / \mathrm{m}^{2}$ $(p<0.01)$. CI continued to show insigni ficant changes till the end of surgery and did not reach the baseline readings.

SVI in DEX group did not show any significant change at different time intervals before and after induction of anesthesia till the end of surgery. In ESM group, SVI decreased significantly to $29 \pm 4 \mathrm{ml} / \mathrm{min} / \mathrm{m}^{2}(\mathrm{p}<0.05)$ at $3 \mathrm{~min}$ of the start of infusion then gradually incr eased insignificantly to $31 \pm 4 \mathrm{ml} / \mathrm{min} / \mathrm{m}^{2}$ at the end of surgery.

SVRI in the DEX group showed a significant increase to about double the baseline reading after $3 \mathrm{~min}$ from the 
start of infusion to $3985 \pm 243$ dyn.s.cm ${ }^{-5} \cdot m^{-2}(p<0.01)$. At 10 min time interval SVRI decreased significantly to $2428 \pm 276$ dyn.s. $\mathrm{cm}^{-5} \cdot \mathrm{m}^{-2}$ and did not show a significant change till the end of surgery. In the ESM group SVRI did not show significant changes during different studied time intervals.

PVRI in both groups did not show statistically significant changes at different studied time intervals.

Table (2): Hemodynamic data of both groups before induction of anesthesia.

\begin{tabular}{|c|c|c|c|c|}
\hline Parameter & Baseline & $\begin{array}{c}3 \text { min after } \\
\text { start of } \\
\text { infusion }\end{array}$ & $\begin{array}{c}10 \text { min after } \\
\text { start of } \\
\text { infusion }\end{array}$ & $\begin{array}{l}\text { Before } \\
\text { Induction }\end{array}$ \\
\hline $\mathrm{HR}(\mathrm{bpm})$ & & & & \\
\hline$D E X$ & $78 \pm 7$ & $70 \pm 6^{*}$ & $77 \pm 9 *$ & $78 \pm 8$ \\
\hline ESM & $74 \pm 6$ & $73 \pm 8$ & $72 \pm 7$ & $72 \pm 5$ \\
\hline $\mathrm{MAP}(\mathrm{mmHg})$ & & & & \\
\hline$D E X$ & $90 \pm 11$ & $101 \pm 13 *$ & $89 \pm 10 *$ & $88 \pm 12$ \\
\hline ESM & $93 \pm 12$ & $87 \pm 14^{*}$ & $86 \pm 9$ & $84 \pm 15$ \\
\hline $\mathrm{CVP}(\mathrm{mmHg})$ & & & & \\
\hline$D E X$ & $9 \pm 3$ & $8 \pm 6$ & $10 \pm 5$ & $11 \pm 4$ \\
\hline ESM & $11 \pm 5$ & $12 \pm 4$ & $11 \pm 7$ & $12 \pm 6$ \\
\hline $\operatorname{MPAP}(\mathrm{mmHg})$ & & & & \\
\hline$D E X$ & $21 \pm 6$ & $20 \pm 5$ & $21 \pm 6$ & $20 \pm 7$ \\
\hline ESM & $23 \pm 7$ & $21 \pm 3$ & $20 \pm 4$ & $21 \pm 8$ \\
\hline $\mathrm{PCWP}(\mathrm{mmHg})$ & & & & \\
\hline$D E X$ & $13 \pm 4$ & $12 \pm 3$ & $12 \pm 4$ & $12 \pm 4$ \\
\hline ESM & $15 \pm 3$ & $13 \pm 4$ & $13 \pm 3$ & $13 \pm 4$ \\
\hline $\mathrm{CI}\left(1 / \mathrm{min} / \mathrm{m}^{2}\right)$ & & & & \\
\hline$D E X$ & $2.6 \pm 0.2$ & $2.2 \pm 0.1 *$ & $2.5 \pm 0.1 *$ & $2.6 \pm 0.1$ \\
\hline ESM & $2.7 \pm 0.1$ & $2.1 \pm 0.3 *$ & $2.2 \pm 0.2$ & $2.3 \pm 0.1$ \\
\hline $\operatorname{SVI}\left(\mathrm{ml} / \mathrm{beat} / \mathrm{m}^{2}\right)$ & & & & \\
\hline$D E X$ & $33 \pm 4$ & $31 \pm 5$ & $32 \pm 4$ & $33 \pm 5$ \\
\hline$E S M$ & $36 \pm 3$ & $29 \pm 4 *$ & $30 \pm 5$ & $32 \pm 5$ \\
\hline SVRI(dyn.s.cm $\left.{ }^{-5} \cdot \mathrm{m}^{-2}\right)$ & & & & \\
\hline$D E X$ & $2292 \pm 251$ & $3985 \pm 243 *$ & $2428 \pm 276^{*}$ & $2384 \pm 346$ \\
\hline$E S M$ & $2398 \pm 246$ & $2478 \pm 311$ & $2494 \pm 324$ & $2483 \pm 375$ \\
\hline PVRI(dyn.s.cm $\left.{ }^{-5} \cdot \mathrm{m}^{-2}\right)$ & & & & \\
\hline$D E X$ & $257 \pm 36$ & $229 \pm 33$ & $251 \pm 34$ & $242 \pm 29$ \\
\hline ESM & $284 \pm 47$ & $273 \pm 41$ & $241 \pm 39$ & $268 \pm 35$ \\
\hline
\end{tabular}

$H R=$ heart rate, MAP=mean arterial pressure, $C V P=$ central venous pressure, $M P A P=$ mean pulmonary artery pressure, $P C W P=$ pulmonary capillary wedge pressure, $C I=$ cardiac index, SVI=stroke volume index, SVRI=systemic vascular resistance, $P V R I=$ pulmonary vascular resistance, ${ }^{*} p<0.05$. 
Table (3): Hemodynamic data of both groups after induction of anesthesia

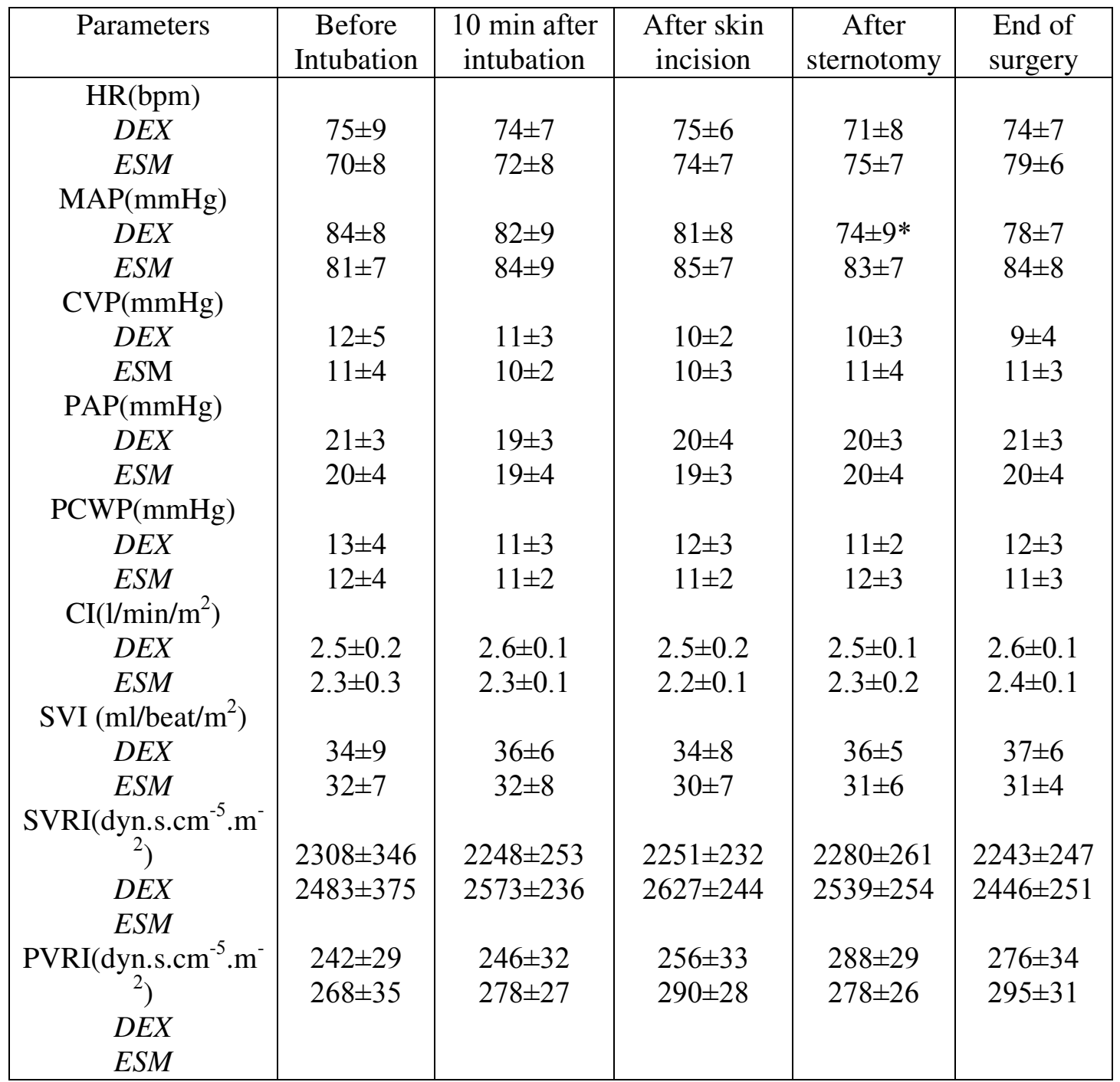

$H R=$ heart rate, $M A P=$ mean arterial pressure, $C V P=$ central venous pressure, $M P A P=$ mean pulmonary artery pressure, $P C W P=$ pulmonary capillary wedge pressure, $C I=$ cardiac index, SVI=stroke volume index, SVRI=systemic vascular resistance, $P V R I=$ pulmonary vascular resistance, ${ }^{*} p<0.05$.

Incidence of hypotension, hypertension, tachycardia, bradycardia, dysrhythmia and ST segment changes:

In DEX group hypotension was observed in 2 patients $(10 \%)$ during the first hour of the start of infusion while in ESM group it happened in 4 patients
(20\%). Hypotension was treated with fluid loading, plasma expanders and vasopressors (ephedrine $5 \mathrm{mg}$ bolus). During DEX infusion no patients developed hypertensive episodes, whereas two patients in ESM group developed hypertensive episodes and 
nitroglycerine infusion was used to control blood pressure (table: 4).

Tachycardia (HR >110 bpm) developed in 2 patients $(10 \%)$ in the ESM group and indral $0.1 \mathrm{mg}$ bolus was used to control the HR while no tachycardia developed in DEX group. There were 4 patients (20\%) developed bradycardia $(\mathrm{HR}<50 \mathrm{bpm})$ in $\mathrm{DEX}$ group and 2 patients $(10 \%)$ in the ESM group that returned to normal with pharmacologic interventions in the form of atropine $0.01 \mathrm{mg} / \mathrm{kg}$.

Myocardial ischemia in the form of ST segment depression was noticed in one patient in the DEX group (5\%) and in 5 patients in the ESM group $(25 \%)$ which was treated by nitrogly cerine infusion as seen in table 4 .

Table (4): Incidence of Hypotension, Hypertension, Bradycardia, Tachycardia, Dysrhythmia and ST depression in both groups.

\begin{tabular}{|c|c|c|c|}
\hline Abnormality & Group & No. of patients & Management \\
\hline Hypotension & DEX & $2(10 \%)$ & fluid challenge, vasopressors \\
\hline$(M A P<60 \mathrm{mmHg})$ & ESM & $4(20 \%)$ & (ephedrine) \\
\hline Hypertension & DEX & 0 & \\
\hline$(M A P>120 m m H g)$ & ESM & $2(10 \%)$ & vasodilators (nitoglycerine) \\
\hline Bradycardia & DEX & $2(10 \%)$ & atropine \\
\hline$(H R<50 \mathrm{bpm})$ & ESM & $4(20 \%)$ & \\
\hline Tachycardia & DEX & 0 & \\
\hline$(H R>110 \mathrm{bpm})$ & ESM & $2(10 \%)$ & indral \\
\hline Dysrhythmia: & & & \\
\hline Junctional rhythm & DEX & $2(10 \%)$ & --- \\
\hline ESM $\quad 0$ & & & \\
\hline Atrial fibrillation & DEX & 0 & \\
\hline ESM $1(5 \%)$ & & defibrillation & \\
\hline ST depression & DEX & $1(5 \%)$ & nitroglycerine \\
\hline $\begin{array}{l}\text { (persistent } S T \\
\text { depression }>0.6 \mathrm{~mm} \text { ) }\end{array}$ & ESM & $5(25 \%)$ & \\
\hline
\end{tabular}

\section{Supplementary Anesthetics}

The mean total number of intraoperative interventions required to maintain the hemodynamic parameters within the predetermined limits was significantly less in the DEX group. The total fentanyl dose was significantly increased in the ESM group per patient $(35.4 \pm 5.1 \mathrm{ug} / \mathrm{kg})$ than in the DEX group $(26.3 \pm 4.3 \mathrm{ug} / \mathrm{kg})$. The total dose of propofol per patient was significantly higher in the ESM group $(935 \pm 52 \mathrm{mg}$ ) than in DEX group ( $810 \pm 43 \mathrm{mg})$. Midazolam $0.1 \mathrm{mg}$ bolus was used more frequently in ESM group to reach a total dose of $9.4 \pm 2.6 \mathrm{mg}$ per patient while rarely used in DEX group.

Fentanyl-induced Muscle Rigidity, Postoperative Shivering, and Diuresis

Five patients $(25 \%)$ in the DEX group and 12 patients $(60 \%)$ in the ESM group had muscle rigidity during or immediately after the induction dose of fentanyl $(\mathrm{P}<0.01)$. Postoperative shiver -ing occurred more frequently in the ESM group than in the DEX group (13 versus 4 patients). The patients of the DEX group excreted more urine than 


\section{Comparison of hemodynamic responses}

did the patients of the ESM group during operation $(1345 \pm 215 \mathrm{ml})$ versus $(975 \pm 589 \mathrm{ml})$.

\section{Discussion}

Alpha2-adrenoceptor agonists, have been widely studied in humans. The prototype clonidine exerts a biph asic effect on arterial blood pressure starting with transient hypertension followed by a longer lasting reduction in blood pressure. ${ }^{11}$ The increase in blood pressure is mediated by an alpha 2-adrenoceptor-induced vasoconstric tive response in the peripheral vascula ture. The blood-pressure-lowering effe cts of clonidine are largely mediated by centrally located receptors in the lateral reticular nucleus and locus ceruleus, which ordinarily mediates a pressor response. $^{12}$ This hypotensive effect is consistent with a resetting of the baroreceptor system to maintain a lower blood pressure. The result is a marked reduction in sympathetic tone and an enhanced parasympathetic outflow. Clonidine's ability to reduce blood pressure is limited to these effects on the autonomic nervous system (e.g., clonidine is not a vasodilator). ${ }^{13}$

Although the bradycardic effect of alpha-2 adrenergic agonists has been known for a long time, the mechanism for this action is in doubt. Alpha-2 adrenergic agonists enhance the barore flex sensitivity to increases in systolic arterial pressure. Clonidine reduces HR by reduced sympathetic tone and the increased vagal tone., ${ }^{9,11}$

Hypertension, tachycardia, arrhy thmias and myocardial ischemia for $\beta$ adrenergic stimulation are common occurrences in coronary artery disease patients in the perioperative period. ${ }^{14}$ Esmolol has been used extensively during $\mathrm{CABG}$ as prophylaxis against hypertension, tachycardia and myocar dial ischemia. Bolus doses ranging from
0.5 to $1.0 \mathrm{mg} / \mathrm{kg}$ have been used follo wed by $6-12 \mathrm{mg} / \mathrm{min}$. These doses have been found to effectively treat increases in HR that occur during

$\mathrm{CABG}$ and to block the $\beta$-adrenergic effects of catecholamines associated with surgical stress. ${ }^{15}$ It produced signi ficant reductions in MAP, HR and $\mathrm{CI}$ in patients with coronary artery disease and the effects were reversed 30 minutes after discontinuation of the infusion. ${ }^{16}$ Other study showed that esmolol was unsuccessful in controlling $\mathrm{HR}$ as it significantly lowered the MAP without decreasing the HR. ${ }^{17}$ The lack of further attenuation of the HR may be related to the inability of esmolol to occupy sufficient additional $\beta$-adrene rgic receptors to produce added $\beta$ blockade in patients on chronic $\beta$ blockers. ${ }^{4}$ Hypotension is common side effect of intravenous esmolol. The incidence of hypotension was higher with esmolol $(36 \%)$ than with propra nolol $(6 \%)$ at equal therapeutic endpo ints. ${ }^{5}$ The cardioselective drugs may cause more hypotension because $\beta_{1}$ induced myocardial depression and the failure to block $\beta_{2}$-prepheral vasodilat ion. Phlebitis may occur at the site of intravenous administration after prolon -ged esmolol infusion. ${ }^{6}$

\section{Hemodynamic Response}

Dexmedetomidine's hemodynamic profile was found to be similar to that previously reported for clonidine. ${ }^{11}$ An initial transient increase in blood press ure, mediated by peripheral vasoconst riction (pressor effect), was followed by a reduction in blood pressure (depressor effect) due to both a centrally and peri pherally mediated sympatholytic action. Dexmedetomidine significantly blunted the responses of MAP and HR to intub ation, skin incision, and sternotomy, decreased the overall variability of 
MAP, and decreased the incidence of hypertension and tachycardia. Previo -usly, Flacke et al. ${ }^{13}$ observed improved hemodynamic stability in patients having CABG who were given clonidine and anesthetized with high-dose sufentanil and supplemental isoflurane, whereas AbiJaoude et al. ${ }^{18}$ did not find any such decrease. A decreased incidence of tachycardia has been a common finding in patients receiving DEX undergoing non-cardiac surgery. ${ }^{10,19}$

Bloor et al. ${ }^{11}$ reported an initial brief increase in MAP associated with marked, but transient reduction in HR 2 min after a 75-mg iv dose of DEX in humans. As this decrease in HR was associated with an increase in systemic blood pressure it is probably mediated by the baroceptor reflex. A reduced infusion rate of DEX may decrease the hypertension and thereby reduce the associated bradycardia. ${ }^{20}$

In the present study, the intraop erative incidence of tachycardia requi ring treatment was more common in the ESM group than in the DEX group. Moreover, in another study, bradycardia was more common in patients with DEX premedication and undergoing abdominal hysterectomy than in patients receiving midazolam premedication. $^{21}$

Alpha-2 adrenergic agonists, in high doses, will depress atrioventricular (AV) nodal conduction. There is a slight prolongation in the $\mathrm{P}-\mathrm{R}$ interval in subjects receiving clonidine, which suggest that the drug be withheld in elderly patients and those with an existing prolongation of the P-R interval or bradycardia. ${ }^{8}$

In another study, there was no difference between ESM and DEX in the incidence of hypotension. However, the volume of fluid challenge needed to maintain adequate filling pressure and to prevent hypotension was slightly greater in the DEX group than in the ESM group. ${ }^{20}$

In the present study, ESM did not control the HR and MAP as DEX. There were fluctuation in the HR, MAP and hemodynamic responses to surgical stimulation were not blunted as in DEX group.

The CO data obtained after the DEX infusion from the present study indicated a marked reduction during the early transient increase in blood pressure. DEX activates peripheral presynaptic apha-2 receptors which serve to reduce the release of catecholamines. In addition there is a reduction in the central sympathetic outflow through action on the regula tory centers in the brainstem. Both the central and peripheral effects contribute to the reduction in catecholamines. ${ }^{19,20}$

Maze et $\mathrm{al}^{12}$ using a flow-directed pulmonary artery thermal dilution catheter, have shown comparable reductions in CO. Bloor et al., ${ }^{11}$ using a two-dimension dopplerechocardiogra phic method, reported a $23 \%$ reduction in CO $60 \mathrm{~min}$ after a single $100-\mathrm{mg}$ dose of DEX. These findings are also consistent with those reported by others after clonidine., 9

There was an approximate doubling of the SVRI during the period of increased arterial blood pressure (initial transient pressor effect) and reduced CI. This marked increase in SVRI was short-lived (less than 2 min). The combined reduction in sympathetic activity and the apparent increased SVRI would be undesirable in patients with impaired cardiac function.

These findings differ from those studies of patients having CABG and who received clonidine, in which either no effect on cardiac index or SVR was seen, or cardiac index was decreased and SVR was increased during induct - 


\section{Comparison of hemodynamic responses}

$\begin{array}{ccc}\text { ion } & \text { of anesthesia and } \\ \text { intubation. }^{18} & \text { These differences may }\end{array}$ be due to the

different alpha-1/alpha-2 selectivity or to different routes of administration of dexmedetomidine and clonidine. If these effects are substantiated, this is further reason to avoid the initial transient effect by using a slower infusion rate or different route of administration. ${ }^{8}$

As no direct myocardial depres sant effects of clonidine or DEX have been found this reduction in CI would be consistent with reduced metabolic demands. ${ }^{22}$

In the present study, CI was decreased in the ESM group than the DEX group. CI was decreased from the start of infusion due to the myocardial depressing effect of ESM and did not reach the preoperative value at the end of surgery. In the ESM group the SVRI did not show a significant changes as in the DEX group.

\section{Anesthetic Requirement}

Some investigators have observed a decreased need for inhalational anesthetics or opioids by administering clonidine in some studies of patients having non-cardiac and cardiac surgical procedures, ${ }^{23}$ but other researchers found no such effect. ${ }^{8}$ The use of DEX has been shown to decrease isoflurane requirements to maintain hemodynamic parameters within predetermined limits, and to reduce the need for opiates in patients having non-cardiac surgery. ${ }^{13}$ In the present study, the DEX infusion reduced the dose of fentanyl and decreased the total dose of propofol.

\section{Dysrhythmias}

Alpha 2-adrenergic agonists are known to increase the gain of the baroceptor system resulting in vagally mediated dysrhythmias. ${ }^{9}$ In DEX treated group these brady-arrhythmia occurred within minutes of the drug infusion. These events were associated with an increase in blood pressure and a reflex-mediated decrease in HR. It is probable that the dysrhythmias may be avoided by minimizing the pressor response by slowing the rate of DEX infusion. ${ }^{8}$ In all likelihood, atropine pretreatment (or any other atropine-like drug) would have prevented these dysrhythmias. Less well conditioned individuals with higher heart rates and lower vagal tone should be less susceptible to bradycardia mediated by increased gain in the baroceptor system. ${ }^{11}$

\section{Myocardial Ischemia and Infarction}

Dorman et al. $^{23}$ and Quintin et $\mathrm{al}^{24}$ reported a decreased incidence and severity of ischemic S-T segment chan ges in patients who were premedicated with clonidine and undergoing $\mathrm{CABG}$, and a similar finding was reported in patients having non-cardiac surgery. In the present study, the DEX infusion was found to be associated with less STsegment changes than ESM group.

\section{Muscle Rigidity, Postoperative} Shivering, and Diuresis

The proposed mechanisms for opioid-induced muscle rigidity are hypercapnia-induced pulmonary vasoc onstriction and lack of normal cardiova -scular compensation of decrea -sed muscle blood flow. ${ }^{25}$ In the present study DEX decreased the incidence of rigidity (although it did not abolish it entirely)

The incidence of postoperative shivering was decreased among patients given DEX. A similar effect has been observed after using clonidine in patients having non-cardiac and cardiac surgery. ${ }^{26}$ Postoperative shivering is potentially harmful because it can increase the systemic oxygen consum ption and, consequently, increase 
cardiac workload. The increased workl -oad may lead to myocardial oxygen supply-demand imbalance.

Alpha 2-adrenergic agonists induce diuresis, possibly by attenuating the secretion of antidiuretic hormone or by blocking its effect on the renal tubules, by inhibiting the release of renin, or by releasing atrial natriuretic peptide. ${ }^{27}$ In the present study, mean urine output was higher for patients in the DEX group, even though more patients in the ESM group received furosemide to promote diuresis. The volume of fluid challenge was slightly higher in the DEX group, but the total volume administered during operation was nearly the same in both groups.

\section{Limitations in Interpreting the Results}

The sample size of 20 patients in each treatment was too small to evaluate reliably differences between treatment groups. Another secondary end point, fentanyl-induced muscle rigidity, was quantified by a subjective assessment of the anesthesiologists as "yes" or "no". This subjectivity limits the value of our finding that DEX attenuates rigidity.

In conclusion, in patients under going beating heart surgery under total intravenous anesthesia, infusion of dexmedetomidine blunted blood press ure response to intubation and surgery, decreased the intraoperative blood pressure variability and the incidence of tachycardia better than emolol. Dexmed -etomidine decreased the incidence of myocardial ischemia, the anesthetic requirements, the incidence of fentanylinduced muscle rigidity, postoperative shivering and increased urine output.

\section{References}

1. Sum CY, Yacobi A, Kartzinel R, Stampfli H. Kinetics of esmolol, an ultrashort acting b-blocker, and of its metabolite. Clin Pharmacol Ther 1983; 34:427-34.

2. Miller DR, Martineau RJ, Wynands JE, Hill J. Bolus administration of esmolol for controlling the hemod -ynamic response to tracheal intubation: the Canadian multicentre trial. Can J Anaesth 1991; 38:849-58.

3. Liu PL, Gatt S, Gugino LD, Mallampati SR, Covino BG. Esmolol for control of increases in heart rate and blood pressure during tracheal intubation after thiopentone and succinylcholine. Can Anaesth Soc J 1986; 33:556-62.

4. de Bruijin NP, Croghwell N, Reves AG. Hemodynamic effects of esmolol in chronically $\beta$-blocked patients undergoing aortocoronary bypass surg ery. Anesth. Analg. 1987; 66:137-41.

5. Abrams J, Allen J, Allin SR. et al. Efficacy and safty of esmolol versus propranolol in the treatment of supraventricular tachyarrhythmias: A multicenter double-blind clinical trial.1985; 110:913.

6. The Esmolol Research Group: Intravenous esmolol for the treatment of supraventricular Tachyarrhythmia: Results of a multicenter, baselinecontrolled safty and efficacy study of 160 patients. Am Heart J.1986; 122:498.

7. Miyazawa K, Fukuyama H, Kamatsu E, Yamaguchi I. Effects of propanolol on myocardial damage resulting from coronary artery occlusion followed by reperfusion. Am Heart J 1986; 111:51924.

8. Jalonen J, Hynynen M, Kuitunen A, et al. Dexmedetomidine an anesthetic adjunct in coronary artery bypass graf ting. Anesthesiology . 1997; 86(2):23145.

9. Aantaa R, Scheinin M: Alpha2-adren ergic agents in anaesthesiology. Acta Anaesthesiol Scand 1993 ; 37:433-48.

10. Talke P, Li J, Jain U, Leung J, Drasner K, Hollenberg M, Mangano DT: Effects of perioperative dexmedetomi -dine infusion in patients undergoing vascular surgery. Anesthesiology 1995;82:62033.

11. Bloor BC, Ward DS, Belleville JP, et al. Effects of intravenous dexme - 


\section{Comparison of hemodynamic responses}

detomidine in humans. II. Hemod -ynamic changes. Anesthesiology 1992 Dec; 77:1134-42.

12. Maze M, Tranquilli W: Alpha-2 adrenoceptor agonists: Defining the role in clinical anesthesia. Anesthe -siology 1991;74:581-605.

13. Flacke JW, Bloor BC, Flacke WE, Wong D, Dazza S, Stead SW, Laks H: Reduced narcotic requirement by clonidine with improved hemodynamic and adrenergic stability in pat -ients undergoing coronary surgery. Anesthesiology 1987;67: 909-17.

14. Nicolson SC, Jobes DR, Quinlan JJ. Cardiovascular effects of esmolol in patients anesthetized with sufentanil pancuronium for myocardial revascula rization. J. Cardiothoracic Anesth. (4 suppl 2)1990; 55.

15. Sheppard S, Eagle CJ, Strunin L. A bolus dose of esmolol attenuates tachy cardia and hypertension after tracheal intubation. Can J Anaesth 1990; 37:2025.

16. Reves JG, Groughwell NG, Hawkins, et al. Esmolol for treatment of intraop erative tachyca rdia and/or hypertension in patients having cardiac operations. J. Thoracic Cardiovasc Surg. 1990; 100:221.

17. Askenazi J, Hoff JV, Turlopaty P, et al. The effects of esmolol on cardiac hemodynamic function. Clin Res.1985; 33:167A.

18. Abi-Jaoude F, Brusset A, Ceddaha A, Schlumberger S, Raffin L, Dubois C, Guilmet D, Fischler M: Clonidine premedication for coronary artery bypass grafting under high dose alfentanil anesthesia: Intraoperative and postoperative hemodynamic study. J Cardiothorac Vasc Anesth 1993;7:3540.

19. Aho M, Scheinin M, Lehtinen AM, Erkola O, Vuorinen J, Korttila K: Intramuscularly administered dexmed etomidine attenuates hemodynamic and stress hormone responses to gynecologic laparoscopy. Anesth Analg 1992;75: $932-9$.
20. Gravel N, Richardson C, Searle N, et al. Hemodynamic, cardiac and neurohormonal interactions of esmolol and dexmedetomidine in 36 healthy volunteers (abstract). Anesth Analg 1999 Apr; 88 Suppl.:25

21. Erkola O, Korttila K, Aho M, Haasio J, Aantaa R, Kallio A: Comparison of intramuscular dexmedetomidine and midazolam premedication for elective abdominal hysterectomy. Anesth Analg 1994 ; 79:646-53.

22. Delaunay L, Bonnet F, Duvaldestin P: Clonidine decreases postoperative oxygen consumption in patients recovering from general anesthesia. $\mathrm{Br} \mathbf{J}$ Anaesth 1991;67: 397 -401.

23. Dorman BH, Zucker JR, Verrier ED, Gartman DM, Slachman FN: Clonidine improves perioperative myocardial ischemia, reduces anesthetic require ment, and alters hemodynamic param eters in patients undergoing coronary artery bypass surgery. J Cardiothorac Vasc Anesth 1993; 7:386-95.

24. Quintin L, Cicala R, Kent M, Thomsen B: Effect of clonidine on myocardial ischemia: A double-blind pilot trial (letter). Can J Anaesth 1993 ;40:85-6.

25. Weinger MB, Segal IS, Maze M: Dexmedetomidine, acting through cen tral alpha-2 adrenoceptors, prevents opiate-induced muscle rigidity in the rat. Anesthesiology 1989; 71: 242-9.

26. Talke P, Tayefeh F, Sessler DI, et al. Dexmedetomidine does not alter the sweating threshold, but comparably and linearly decreases the vasoconstriction and shivering thresholds. Anesthesiology 1997 Oct; 87:835-41.

27. Hamaya $Y$, Nishikawa T, Dohi S: Diuretic effect of clonidine during isoflurane, nitrous oxide, and oxygen anesthesia. Anesthesiology 1994; 81 : 811-19. 
مقارنة تأثير الاكسمديتوميدين و الإسملول على نشاطية الام

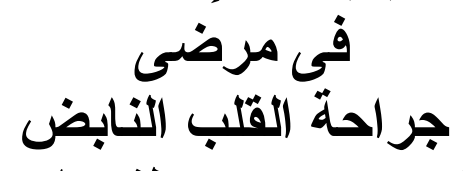

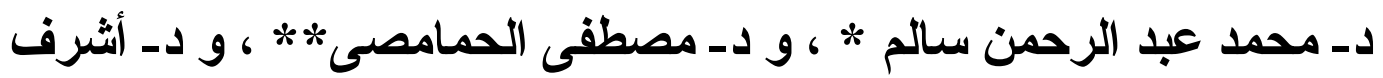

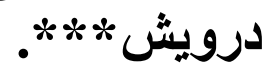

قسم التخدير كلية الطب جامعة المنوفية * ، قسم التخدير كلية الطب جامعة القاهر فرع الفيوم

$$
\text { قسم التخدير معهد بحوث الرمد }
$$

خلقبـة البحث: محقذات مستقبلات الفـا تقلل مـن النشـاط السيمبتاوى و ينشـأ عن ذلك

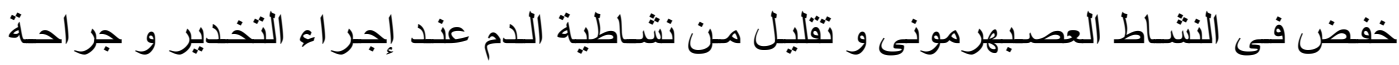

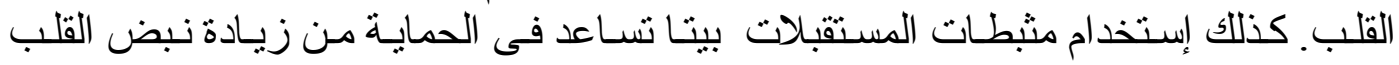

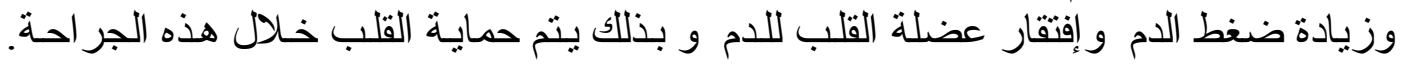

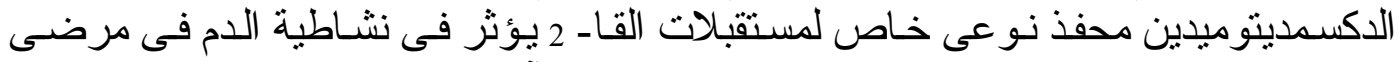

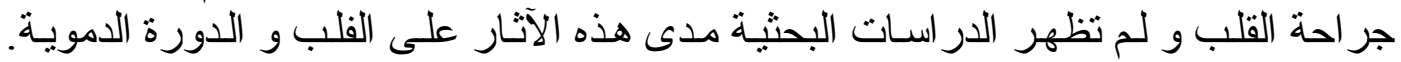

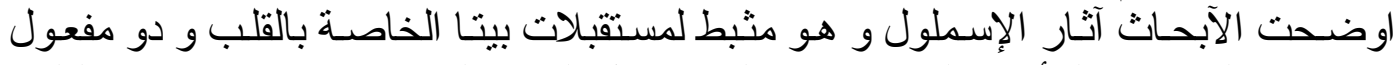

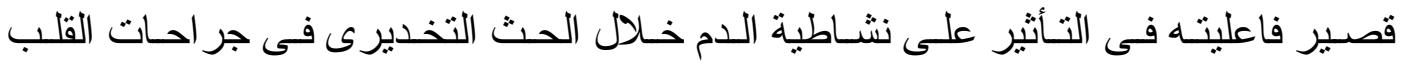

الهذف: مقارنة آثار الدكسميتومدين(الدكس) و الإسملول على نشـاطية الدم و كميات أدويـة

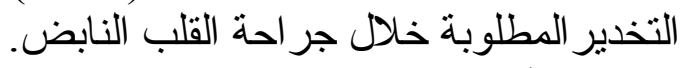

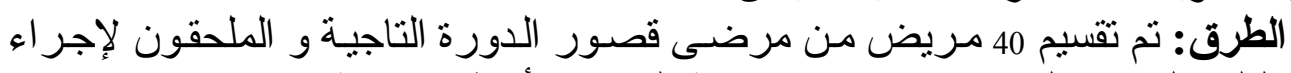

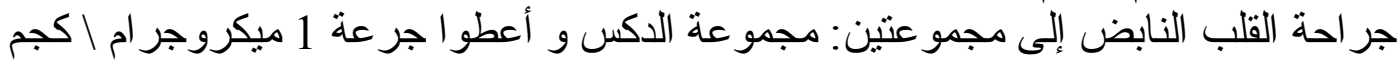

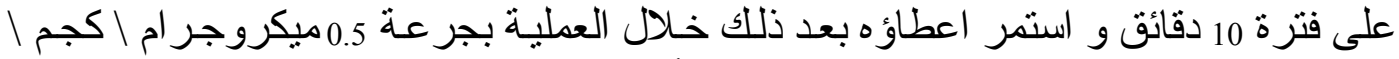

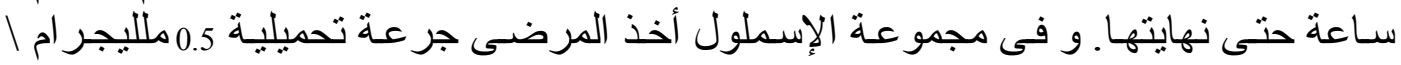

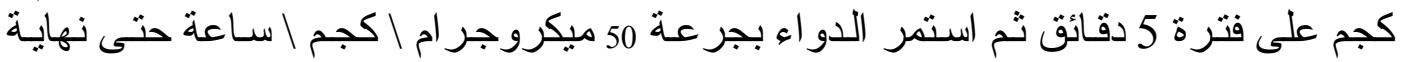

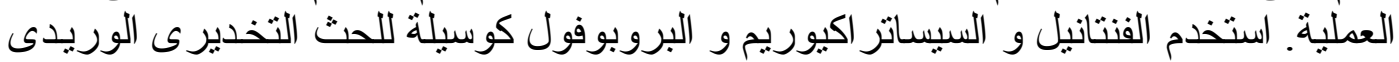

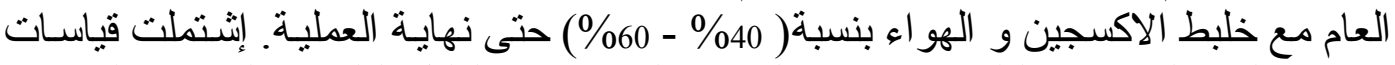
نشاطية الدم على نبض القلب و متوسط الضغط الثريانى و الدليل القلبى و المقاومة الو الو عائية

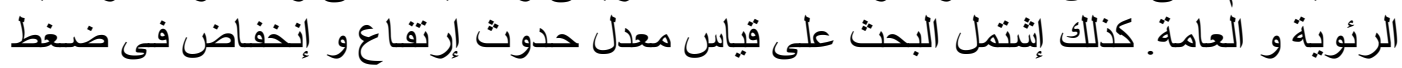
الدم و زيـادة او إنخفاض نبض القلب و حدوث إضطر اب فى نبض القلب و تغير ات في في

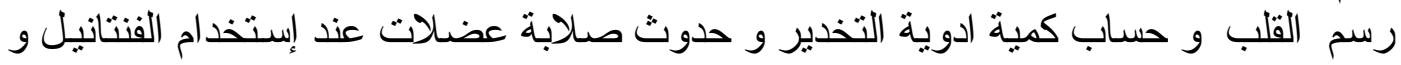
حدوث رعثة بعد العملية. النتائج: قلل الدكس بدرجة ملحوظة نبض القلب و الدليل القلبى بعد 3 دقائق إلى

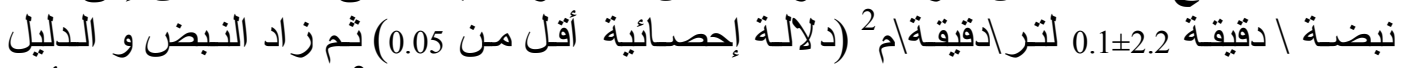

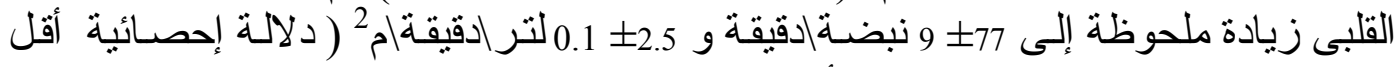

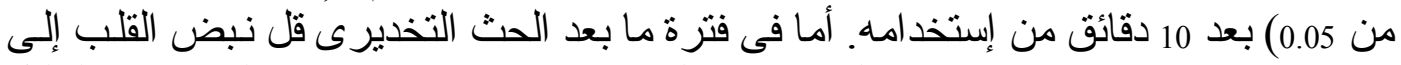

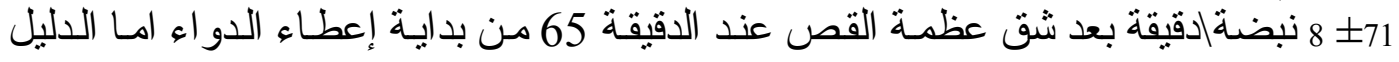




\section{Comparison of hemodynamic responses}

القلبى فستمر فى النقصان بشكل غير ملحوظ إحصـائيا حتى عـاد إلى مسنتوى بدايـة الإية

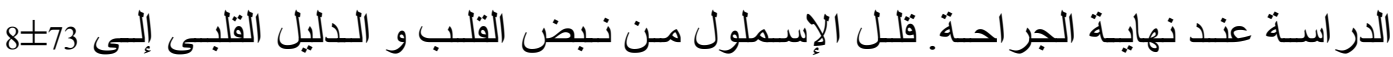

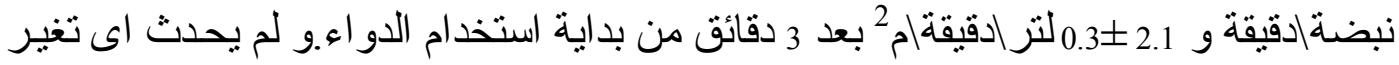

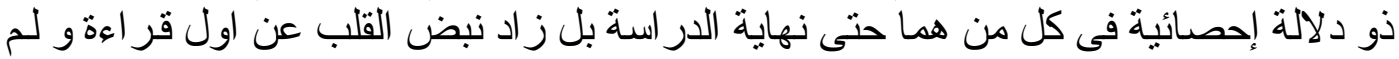

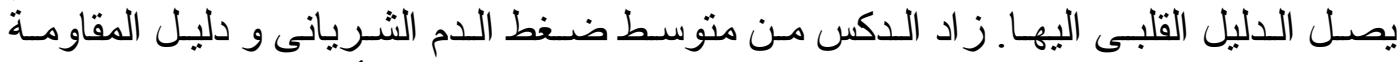

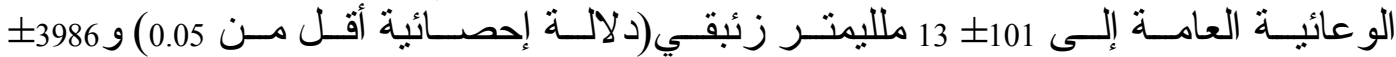

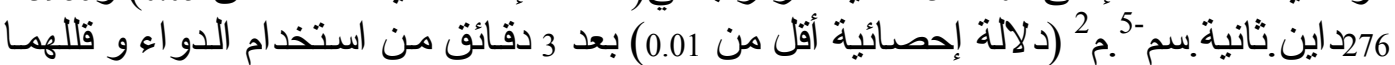

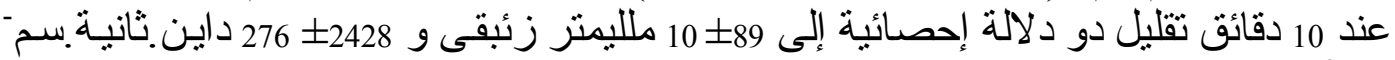

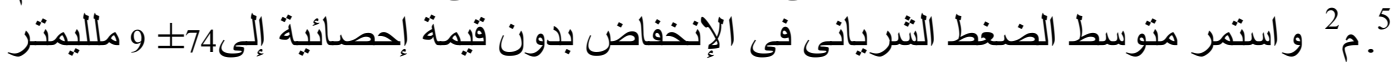

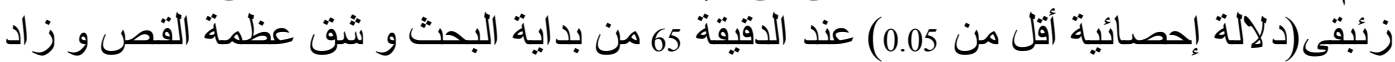

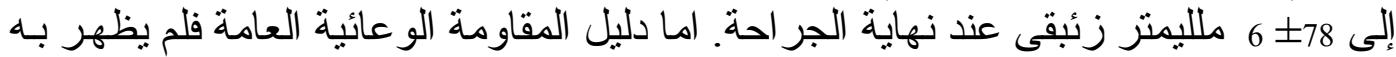

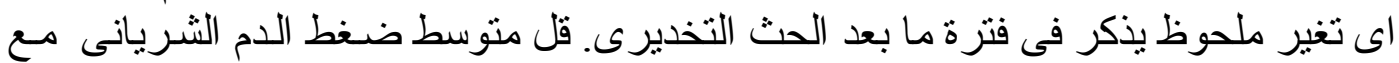

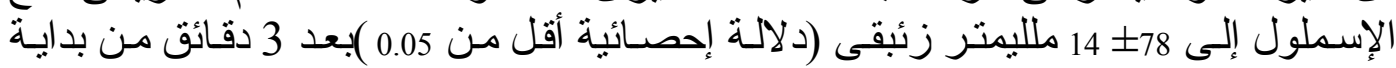

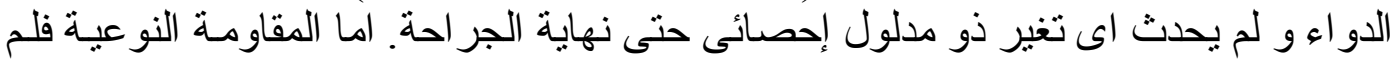

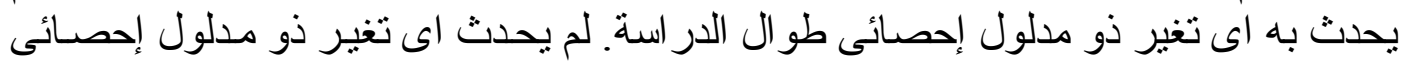

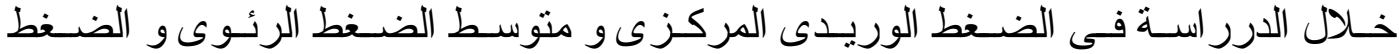

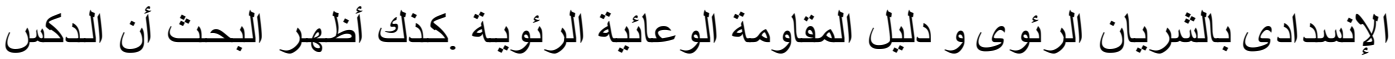

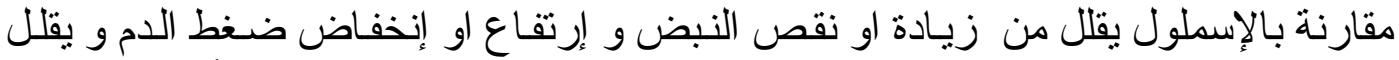

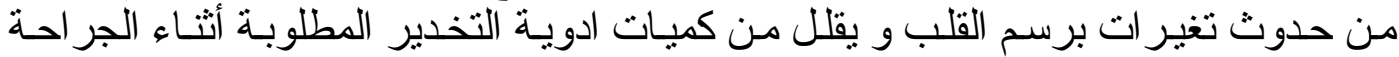

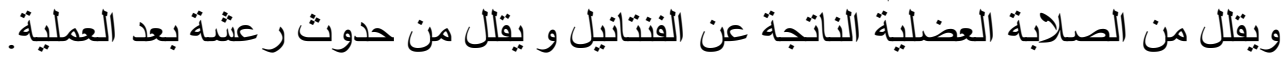

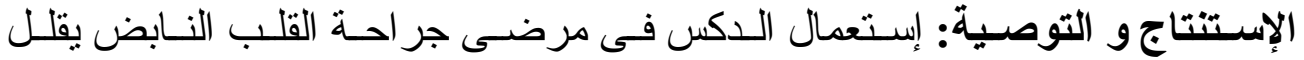

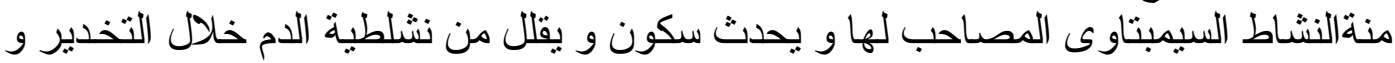

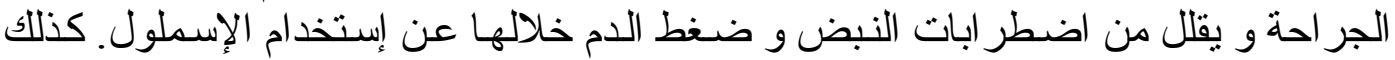

يقلل من كمية التخدير المطلوبة و حدوث رعشة بعد العملية و حدوث صلابة عضلية. 